\title{
Are severe acute retinopathy of prematurity and severe periventricular leucomalacia both ischaemic insults?
}

\author{
Y K NG,' A R FIELDER,' M I LEVENE,' J Q TROUNCE, ' AND N MCLELLAN \\ From the 'Departments of Child Health and Ophthalmology, University of Leicester Medical School, and \\ ${ }^{2}$ Department of Child Health, University of Nottingham Medical School
}

SUMMARY Over a period of 20 months six preterm infants have been seen who developed severe acute retinopathy of prematurity (ROP) and who also had ultrasound evidence of extensive cerebral parenchymal changes compatible with severe periventricular leucomalacia. Only one of these infants had a birthweight of less than $1000 \mathrm{~g}$, and their gestational ages ranged from 27 to 30 weeks. The association between these two important complications of preterm birth has led us to postulate that an episode of hypoperfusion of the cerebral circulation sufficient to result in cerebral ischaemia could also reduce an already compromised ocular blood flow and further exacerbate retinal ischaemia, thereby increasing the severity of ROP.

Periventricular leucomalacia (PVL), and retinopathy of prematurity (ROP) are both important common complications of preterm birth. Over a two-year period we have noticed the association of severe acute ROP with extensive cerebral intraparenchymal lesions. Both conditions are thought to be ischaemic in nature, and in this article we explore the possibility that the insult responsible for the cerebral ischaemia could also increase the severity of the retinopathy.

\section{Patients and methods}

All infants in two neonatal intensive care units (Leicester Royal Infirmary and Nottingham University Hospital) have regular cranial ultrasound scans and ophthalmic examinations. All scans are performed with a real-time sector scanner, fitted with a $5 \mathrm{MHz}$ or $7.5 \mathrm{MHz}$ transducer. Eye examinations are carried out at weekly intervals from 3 weeks of age, by one of us (ARF) using indirect ophthalmoscopy, speculum and scleral indentation, following pupillary dilatation with $0.5 \%$ cyclopentolate eyedrops.

Correspondence to Professor A R Fielder, Birmingham and Midland Eye Hospital, Church Street, Birmingham B3 2NS.

\section{Results}

Over a period of 20 months 299 infants were examined in the two neonatal units, and six infants were found to have extensive cerebral parenchymal abnormalities together with severe ROP. The records of each of the six infants were examined, and seven indicators of neonatal illness were extracted. These were an Apgar score $<5$ at 5 minutes, the duration of assisted ventilation, the occurrence of pneumothorax, the presence of a persistent ductus arteriosus (PDA) requiring treatment, proved septicaemia, exchange transfusions, and the number of blood transfusions. Many factors have been reported to be associated with ROP, and include some of those described above.

Each of the six patients was matched with an infant of the same gestational age who had sustained so far as practically possible the identical indicators of neonatal illness listed above. Cranial ultrasound findings and severity of ROP were noted for both groups of infants. The details of both groups of infants are summarised in Tables 1 and 2 . Four of the six study infants had clinical evidence of an episode of circulatory collapse. All six of the study patients had intraventricular haemorrhage (IVH) with echodensities in the periventricular areas and subsequent cyst 
Table 1 Details of the six study infants

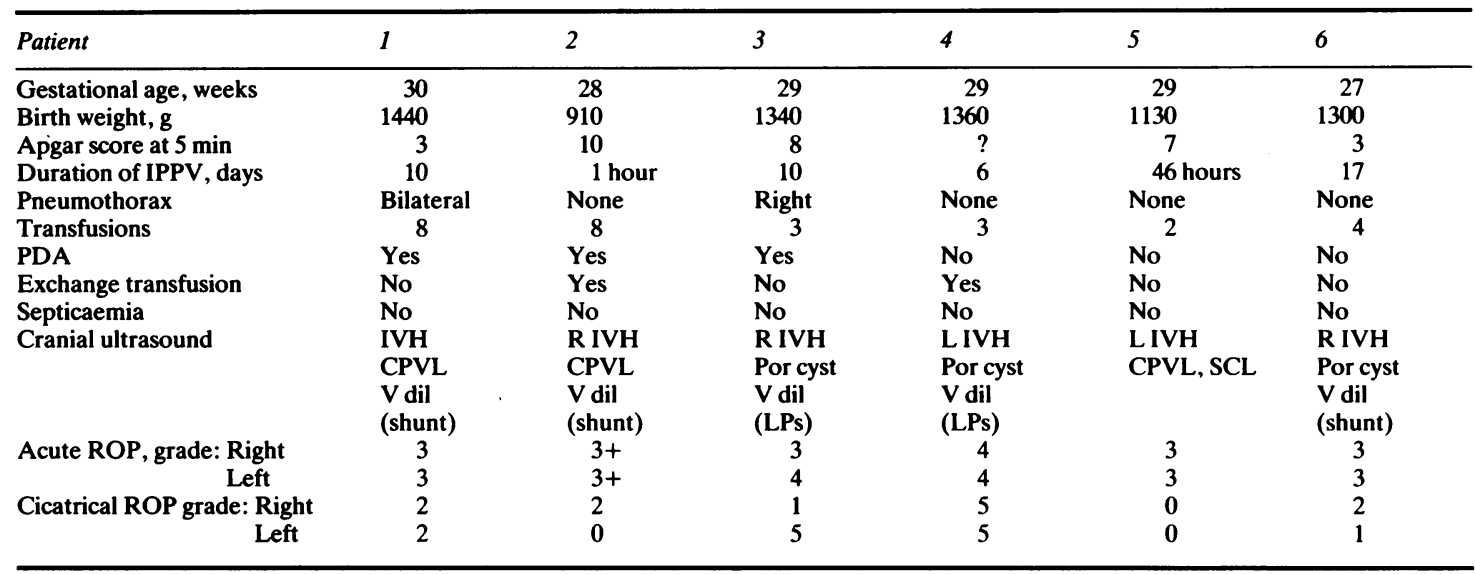

IPPV=intermittent positive pressure ventilation. $\mathrm{PDA}=$ persistent ductus arteriosus requiring therapy. IVH=intraventricular haemorrhage $\mathrm{CPVL}=$ cystic periventricular leucomalacia. Por cyst $=$ porencephalic cyst. $\mathrm{SCL}=$ subcortical leucomalacia. Shunt $=$ insertion of ventriculoperitoneal shunt. $\mathrm{LPs}=$ serial lumbar punctures. $\mathrm{V}$ dil =ventricular dilatation.

formation with ventricular dilatation. Five required treatment for progressive ventriculomegaly. Among the comparison group of infants four had IVH without periventricular echodensities and two developed ventricular dilatation, one of whom required a ventriculoperitoneal shunt. One infant (comparison infant 5) was found to have an area of echodensity in the periventricular white matter. This persisted for more than two weeks, but cysts did not develop. One infant in the comparison group had normal ultrasound scans throughout.

The eye findings are shown as the most severe grade of acute and cicatricial ROP in each eye (Tables 1 and 2). The grading system used is that of the International Classification of ROP. ${ }^{1}$ Four of the patients we are reporting on had stage 3 acute ROP, one had stage 4 in both eyes, and the sixth had stage 3 in the right and stage 4 in the left eye. In the comparison group four infants had acute ROP stage 1 and two infants had normal eyes. None of this group developed cicatricial ROP.

Arterial oxygen readings $\left(\mathrm{PaO}_{2}\right)$ for each infant were analysed. A curve was plotted for $\mathrm{PaO}_{2}$ against the time of sampling for each infant. The area under the curve was measured above a level of $15 \mathrm{kPa}$ and also below that level, as illustrated in Fig. 1. The area above (area $\mathrm{A}$ ) expressed as a proportion of the total area above and below $15 \mathrm{kPa}($ area $A+B)$ can be used as an estimate of the proportion of time above this level and also takes into account the severity of

Table 2 Details of the six study infants in the comparison group

\begin{tabular}{|c|c|c|c|c|c|c|}
\hline Comparison patient & 1 & 2 & 3 & 4 & 5 & 6 \\
\hline Gestational age, weeks & 30 & 28 & 29 & 29 & 29 & 27 \\
\hline Birth weight, $g$ & 1320 & 720 & 1370 & 1020 & 1200 & 830 \\
\hline Apgar score at $5 \mathrm{~min}$ & 8 & 8 & 6 & 6 & 8 & 8 \\
\hline Duration of IPPV, days & 9 & 0 & 7 & 7 & 2 & 18 \\
\hline Pneumothorax & Bilateral & None & Left & None & None & None \\
\hline Transfusions & 1 & 8 & 1 & 4 & 1 & 4 \\
\hline PDA & Yes & Yes & & & & Yes \\
\hline Exchange transfusion & No & No & No & No & No & No \\
\hline Septicaemia & No & No & No & Yes & No & Yes \\
\hline Cranial ultrasound & IVH & Normal & $\begin{array}{l}\text { IVH } \\
\text { V dil } \\
\text { (shunt) }\end{array}$ & IVH & Prolonged flare & $\begin{array}{l}\text { IVH } \\
\text { V dil } \\
\text { (no treatment) }\end{array}$ \\
\hline Acute ROP, grade & 1 & Normal & 1 & 1 & Normal & 1 \\
\hline Cicatrical ROP grade & 0 & 0 & 0 & 0 & 0 & 0 \\
\hline
\end{tabular}

IPPV=intermittent positive pressure ventilation. PDA = persistent ductus arteriosus requiring treatment. IVH=intraventricular haemorrhage. Shunt=insertion of ventriculo-peritoneal shunt. Prolonged flare=echodensity in periventricular region persisting for more than two weeks which did not develop into cysts. $V$ dil =ventricular dilatation. 


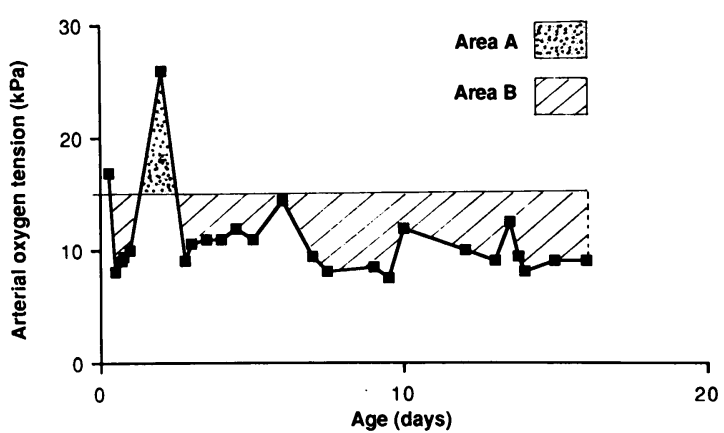

Fig. 1 Graph of arterial oxygen tension plotted against age, for study patient 4 , to illustrate method of estimating hyperoxia. Hyperoxia estimate $=$ area $A / a r e a A+B$.

hyperoxia. In both groups the median proportion of time above $15 \mathrm{kPa}$ was 0.02 , and there was no significant difference between them $(p=0 \cdot 69$, MannWhitney U test).

\section{Discussion}

We have presented the details of six infants and six comparison infants who were matched for gestational age and seven indicators of neonatal illness. The comparison group did not suffer ischaemic brain damage, and four of the six developed mild acute ROP, whereas all six of the patient group suffered severe cerebral intraparenchymal lesions and all six developed severe acute ROP. Complete resolution occurred in only one (case 5), and the remaining five account for all but one of the most severe cases of cicatricial ROP seen in the 299 babies examined in the two neonatal units in question over the 20month period of this study. These infants therefore represent an unusually severe subgroup, and it is interesting to note that only one of the six had a birthweight under $1000 \mathrm{~g}$, a group recognised to be particularly at risk of ROP. ${ }^{23}$

From these observations we have developed a hypothesis which may explain the severity of ROP in our infants. It is generally acknowledged that ROP has an ischaemic basis, but we suggest that these infants suffered an additional ischaemic event, further upstream in the carotid circulation, resulting in the cerebral ischaemic lesion, periventricular leucomalacia, and a significant increase in the severity of acute ROP.

There have been many reported associations of neonatal events with the occurrence of ROP, of which oxygen exposure is the best known. We analysed the recorded arterial oxygen values of the six study infants and of those in the comparison group and found that there was no significant difference between them when the area under the $\mathrm{PaO}_{2}$ curve was used to measure the degree of hyperoxia experienced by the infants. Hyperoxia is difficult to quantify over a prolonged period in a rapidly changing clinical situation, and the method we used is open to criticism for oversimplification, as $\mathrm{PaO}_{2}$ levels fluctuate and the sampling intervals are necessarily variable. Despite these clinically inevitable shortcomings, this method has provided an estimate of documented hyperoxia and allowed comparison between the two groups. It is recognised that not all infants with hyperoxia develop ROP, ${ }^{4}$ and other factors apart from oxygen are also important, such as the severity of illness in the neonatal period. ${ }^{56}$

Intraventricular haemorrhage has been reported in association with ROP by Procianoy et al. ${ }^{7}$ They diagnosed IVH by computerised cranial tomography but did not describe periventricular changes, though some of their patients did have ventricular dilatation. Since then the use of ultrasound imaging has become more precise, and characteristic appearances of PVL have been described in detail. ${ }^{8}$ PVL occurs in the so-called watershed regions within the periventricular white matter least well supplied by the developing arterial circulation. These areas are particularly susceptible to a critical fall in cerebral perfusion.9 There is now a body of evidence to support the suggestion that most intraparenchymal 'haemorrhagic' lesions are also basically ischaemic in nature, with secondary bleeding into infarcted areas. ${ }^{1111}$ Four of our patients showed the classical ultrasound appearance of cystic $\mathrm{PVL}^{8}$ together with intraventricular haemorrhage. There was clinical evidence of circulatory collapse in four infants, and the cranial ultrasound appearances in all six infants are compatible with severe ischaemic infarction.

The retina of full-term infants is supplied by both the choroidal and retinal vessels, but in the fetus this is not so. The retinal vasculature begins to develop only at the 16th week of intrauterine $\operatorname{life}^{12}$ and progresses centrifugally from the optic disc, reaching the temporal periphery just after term. During early fetal life the retina receives its nutrients from the choroidal circulation, and although this contribution decreases as the retinal vasculature develops the choroid continues to supply the outer portion of the retina throughout life. Since ROP develops at the junction of the vascularised and yet-to-be vascularised retina, it occurs in an area particularly vulnerable to changes in blood flow. Lucey and Dangman ${ }^{5}$ have described two infants who developed severe blinding ROP. In one of these infants there was no cerebral blood flow for seven minutes and the other suffered a cardiac arrest for several minutes. These authors considered that the severe ROP seen in these two infants could be due to cerebral and retinal hypoperfusion. 
Our patients were matched as closely as is clinically possible in a retrospective study with those in the comparison group for seven indicators of neonatal illness. Although severe ROP and severe cerebral ischaemic changes may be associated merely as two unrelated consequences of severe illness in the preterm infant, these conditions could be related through a final common pathway initiated by ischaemia.

An ischaemic hypothesis for the production of ROP was first suggested by Rubinstein in $1952^{13}$ and is an essential component of the theory proposed by Ashton et al. in $1953^{14}$ and discussed again by Ashton in $1980 .{ }^{15}$ These authors showed that destruction of growing retinal vessels by oxygen, the vasoobliterative phase of ROP, rendered the retina ischaemic and led to the vasoproliferative phase. In a recent review Garner and Kissun ${ }^{16}$ stated that 'there is now direct as well as indirect support for the concept that proliferative retinopathy is a consequence of impaired retinal circulation.' Hungerford et al. ${ }^{17}$ also suggested that ROP and cerebral damage may both have an ischaemic basis. Twenty-five years ago Banker and Larroche ${ }^{18}$ noted an association between spastic diplegia due to PVL in preterm infants, and they postulated that ischaemic damage secondary to oxygen toxicity might be the final common pathway in both conditions.

Retinal ischaemia is recognised as the likely basis of ROP, and four of six of the comparison group developed minor retinal changes. Yet although the patient and comparison groups were clinically matched, and there was no significant difference in the oxygen exposure to the two groups, our six patients unlike the six 'controls' developed both severe ROP and cystic PVL. Additional factors must be involved. Both the cerebral and ocular circulations arise from the internal carotid artery, and therefore an episode which causes hypoperfusion of the cerebral circulation sufficient to result in cerebral ischaemia could also reduce an already compromised ocular blood flow. Although the retinal vessels are capable of autoregulation, the choroidal circulation is not, ${ }^{1920}$ with the consequence that, when there is a reduction of flow in the carotid artery, flow through the choroidal system could also fall, thereby exacerbating ischaemia of the overlying retinal tissuesessentially the mechanism suggested for the two patients of Lucey and Dangman. ${ }^{5}$

We are not proposing that ischaemia due to cerebral hypoperfusion is the sole cause of ROP; indeed four of the comparison infants who did not suffer cerebral ischaemia developed mild acute ROP. But cerebral hypoperfusion resulting in ischaemia is considered to be the basis of PVL, and we suggest that in some infants it may also exacerbate the already ischaemic retina and be a major factor contributing not to the initiation but to the severity of the retinal condition.

We are grateful to Professor D Hull for allowing us to report two of the patients under his care. We thank Mr D E Shaw for his help with analysing the data and Mrs M Hopson for secretarial assistance.

Dr Y K Ng is supported by the Medical Research Council.

\section{References}

1 Garner A, chairman of international committee, et al. An international classification of retinopathy of prematurity. Pediatrics 1984; 74: 127-33.

2 Gunn TR, Aranda JV, Little J. Incidence of retrolental fibroplasia. Lancet 1978; i: 216-7.

3 Yu VYH, Hookham DM, Nave JRM. Retrolental fibroplasia controlled study of 4 years' experience in a neonatal intensive care unit. Arch Dis Child 1982; 57: 247-52.

4 Aranda JV, Sweet AY. Sustained hyperoxemia without cicatricial retrolental fibroplasia. Pediatrics 1974; 54: 434-7.

5 Lucey JF, Dangman B. A reexamination of the role of oxygen in retrolental fibroplasia. Pediatrics 1984; 70: 82-96.

6 Flynn JT. Retrolental fibroplasia: update. Trans New Orleans Acad Ophthalmol 1986: 293-325.

7 Procianoy RS, Garcia-Prats JA, Hittner HM, Adams JM, Rudolph AJ. An association between retinopathy of prematurity and intraventricular hemorrhage in very low birth weight infants. Acta Paediatr Scand 1981; 70: 473-7.

8 Trounce JQ, Rutter N, Levene MI. Periventricular leucomalacia and intraventricular haemorrhage in the preterm neonate. Arch Dis Child 1986; 61: 1196-202.

9 Volpe JJ. Cerebral blood flow in the newborn infant: relation to hypoxic-ischemic brain injury and periventricular hemorrhage. J Pediatr 1979; 94: 170-3.

10 Volpe JJ, Herscovitch P, Perlman JM, Raichle ME. Positron emission tomography in the newborn: extensive impairment of regional cerebral blood flow with intraventricular hemorrhage and hemorrhagic intracerebral involvement. Pediatrics 1983; 72: $589-601$.

11 Rushton DI, Preston PR, Durbin GM. Structure and evolution of echodense lesions in the neonatal brain: a combined ultrasound and necropsy study. Arch Disc Child 1985; 60: 798-808.

12 Ashton $\mathrm{N}$. Retinal angiogenesis in the human embryo. Br Med Bull 1970; 26(2): 103-6.

13 Rubinstein K. Mechanism of retrolental fibroplasia. $\mathrm{Br} J$ Ophthalmol 1952; 36: 303-12.

14 Ashton N, Ward B, Serpell G. Role of oxygen in the genesis of retrolental fibroplasia. Br J Ophthalmol 1953; 37: 513-20.

15 Ashton N. Oxygen and the retinal blood vessels. Trans Ophthalmol Soc UK 1980; 100: 359-62.

16 Garner A, Kissun R. The role of ischaemia in the pathogenesis of retinal neovascularisation. In: BenEzra D, Ryan SJ, Glaser BM, Murphy RP, eds. Ocular circulation and neovascularisation. Dordrecht: Martinus Nijhoff/Dr W Junk, 1987: 131-4 (Doc Ophthalmol Proc series 50).

17 Hungerford J, Stewart A, Hope P. Ocular sequelae of preterm birth and their relation to ultrasound evidence of cerebral damage. $B r J$ Ophthalmol 1986; 70: 463-8.

18 Banker BQ, Larroche J-C. Periventricular leucomalacia of infancy. Arch Neurol 1962; 7: 386-410.

19 Flower RJ. Perinatal retinal vascular physiology. In: Silverman WA, Flynn TJ, eds. Retinopathy of prematurity. Boston: Blackwell, 1985: 97-120 (Contemporary Issues in Fetal and Neonatal Medicine no.2).

20 Peeters LLH, Sheldon RE, Jones MD, Jr, Battaglia FC. Retinal and choroidal blood flow in stressed and unstressed fetal and neonatal lambs. Pediatr Res 1980; 14: 1047-52.

Accepted for publication 14 January 1988. 